\title{
Transfer between nonreward and delay of reward following minimal acquisition training
}

\author{
MITRI E. SHANAB and GERALD CAVALLARO* \\ Californio State University, Fresno, California 93710
}

\begin{abstract}
Four groups of rats were given six acquisition trials under continuous reward, continuous delay of reward, partial reward, or partial delay of reward, following which all Ss received continuous delay. It was found that the partial reward and the partial delay of reward groups were significantly more persistent during the shift phase than the continuous reward group. No differences were found over trials between either the two partial groups or between each one and the continuous delay group.
\end{abstract}

According to Amsel (1972), persistence develops whenever an organism learns through counterconditioning to maintain an ongoing response under conditions that usually evoke competing or disruptive responses. Numerous studies have shown that significant transfer takes place between fear and frustration (Wagner, 1969), between fear of electric shock and loud noise (Terris \& Wechkin, 1967), between partial reward and partial goal blocking (Glazer \& Amsel, 1970), and between nonreward and delay (Shanab, 1971). In all foregoing studies, the test for transfer was introduced following a fairly large number of training trials given under persistence-producing conditions.

Several studies have shown that persistence as reflected by the partial reinforcement effect in extinction (PREE) occurs following a small number of acquisition trials (McCain, 1966; Amsel, Hug, \& Surridge, 1968; Capaldi \& Waters, 1970). However, the literature of small-trial phenomena is conspicuous in its lack of studies investigating transfer effects between various persistence-producing operations. The present study was designed to investigate transfer effects between nonreward and delay of reward following minimal acquisition training. By using large reward in the form of multiple pellets. the present study sought to replicate with few (six) trials what the earlier study (Shanab, 1971) obtained with many (56) trials. Such transfer would be predicted on the assumption that multiple rewards result in the fast conditioning of both anticipatory reward $\left(\mathrm{r}_{\mathrm{R}}-\mathrm{s}_{\mathrm{R}}\right)$ and conditioned frustration ( $\mathrm{r}_{\mathrm{I}}-\mathrm{s}_{\mathrm{I}}$ ) mechanisms (Amsel et al. 1968). Conceptually. the process mediating such transfer is very similar to that mediating persistence in extinction following partial reinforcement training. In both cases, it can be argued, conditioned frustration, whether resulting from nonreward or from delay of reward. is the mediator of persistence behavior during either continuous nonreward or delay of reward. Shanab (1971) has shown that

\footnotetext{
*Requests for reprints should be sent to Mitri E. Shanab. Department of Psychology. California State University. I resno. California 93710 .
}

conditioned frustration resulting from delay of reward accounted for the greater persistence during continuous delay by Ss that previously received either partial reward or partial delay of reward relative to control Ss that received continuous reward. Thus, it is predicted in this study that, following a small number of training trials with multiple pellets, partially rewarded and partially delayed Ss would persist longer during continuous delay conditions than continuously rewarded Ss, while both partial groups would perform at the same level.

\section{METHOD}

\section{Design}

The study consisted of two phases. In Phase 1 a 2 by 2 factorial design consisting of two levels of schedule (partial and continuous) and two levels of delay ( 0 - and 15 -sec delay) was used, yielding the following four groups: continuous reward. partial reward, continuous delay, and partial delay of reward. In Phase 2 all Ss received continuous delay of reward.

\section{Subjects}

The Ss were 32 male albino rats of the Sprague-Dawley strain. approximately 90 days old at the beginning of the experiment.

\section{Apparatus}

A $1.5-\mathrm{m}$ runway made of unpainted redwood was used. The runway was covered with Plexiglas and was $23 \mathrm{~cm}$ high and $10 \mathrm{~cm}$ wide throughout. The startbox was $18 \mathrm{~cm}$ long and $17 \mathrm{~cm}$ wide. The goalbox was L-shaped. The initial section of the goalbox was $30.5 \mathrm{~cm}$ long and $15 \mathrm{~cm}$ wide. At right angles to this section was a $16 \times 16 \mathrm{~cm}$ section in which the foodcup was placed. This prevented the $S$ from making any visual discrimination as to whether or not the foodcup was baited. Four sets of photocells were installed in the runway. Interruption of any of the four photobeams started and/or stopped any one of the three Standard Electric timers that measured start. run, and goal times. The fïrst. second, third. and fourth photocells were located 6.5. 21.5.103. and $115 \mathrm{~cm}$ from the startbos, respectively. The start- and goalboses were xparated by two guillotine doors.

\section{Procedure}

Ipon arrival from the vupplier. Sw llẹre placed on free fecdin! 


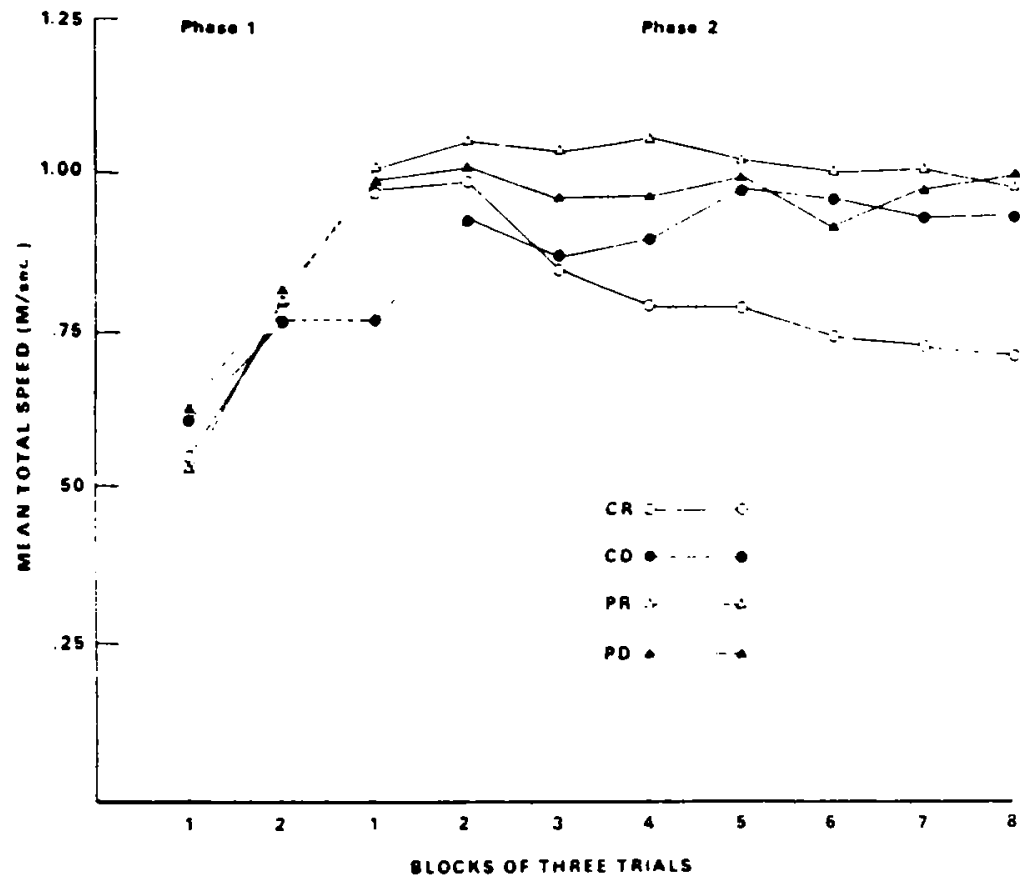

Fig. 1. Mean total running speed as a function of partial delay (PD). partial reward (PR), continuous reward (CR), or continuous delay (CD) in Phase 1 and as a function of a shift from either PD, PR, or $\mathrm{CR}$ to $\mathrm{CD}$ in Phase 2.

for 14 days. following which they were placed on a restricted daily ration of $12 \mathrm{~g}$ of Purina Lab Chow: Where applicable. proper adjustment for food consumed in the apparatus was made to equate for drive level. Nater was available at all times in $S^{\circ}$ s home cage. During the third week of deprivation. each $S$ was handled and allowed to eat a few loyes pellets from a $10-\mathrm{cm}$-diam glass cup later used in the goalbox. Following this period. cach $\mathrm{S}$ was allowed to explore the unbaited apparatus for 2 min per day for 2 days with all circuitry turned off. Then. to adapt $S$ to the various noises of the relays and clocks. all circuitry was turned on and each $S$ received an additional 3 days of exploration for $3 \mathrm{~min}$ per day. Following the exploration period. Phave 1 began and lasted for 6 days, during which each $S$ received one trial per day. each according to its group. The Ss were run in squads of eight that consisted of two $S$ f from each group. The reinforcer consisted of $2245-\mathrm{mg}$ Noyes food pellets. The sequence of reward and nonreward or delayed reward was the same for both partial groups. Specifically, Ss in both groups tirst recejved two rewarded trials followed by three nonrewarded or delayed trials. while the last trial was a rewarded trial. On delayed trials. S ran to an empty goalbox and $15 \mathrm{sec}$ later the baited cup was lowered into the terminal section of the goalbox. To control for secondary reinforcement effects resulting from any lingering food smell. an empty glass cup that was otherwise identical in all respects to the cup used on rewarded trials was placed in the terminal section of the goalbox on nonrewarded trials. The $\mathrm{S}$ was removed from the goalbox $15 \mathrm{sec}$ after interrupting the last photobeam on nonrewarded trials and returned to its home cage. The $S s$ in the continuous reward group were rewarded on each trial. For Ss in the continuous delay group. the treatment was the same as that for the Ss in the partial delay group on delayed trials. On rewarded and delayed trials all $\mathrm{Ss}$ were removed from the goalbox immediately following consumption of the reinforcer. On all trials. as soon as the $S$ broke the last photobeam. the guillotine door was lowered to prevent the $S$ from retracing. In Phase 2 each $S$ received one delayed trial per day for 24 days. The procedure was identical to the one used in Phase 1 on delayed trials. The trials were separated in both phases by $24-h$ ITIs.

\section{RESULTS}

Since the running speeds in the three sections of the runway were generally similar, all analyses reported here are based on mean total speed only. The results, in terms of this measure, are shown in Fig. 1.

\section{Phase 1}

A two-way analysis of variance performed on the data for the last trial of Phase 1 revealed nonsignificant differences for both schedule and delay, as well as the interaction between these two factors (all Fs $<1$ ).

\section{Phase 2}

Figure 1 shows that both the partial reward and partial delay groups ran faster than the continuous reward group when shifted to continuous delay, while both partial groups and the continuous delay group ran at comparable speeds. An analysis of variance test performed on mean total speed over all eight blocks of Phase 2 revealed a significant schedule effect $[F(1.28)=5.74, p<.05]$. Neither the delay nor the Schedule by Delay interaction was significant: $F<1$ for delay and $F(1,28)=1.13 . p>.05$ for the interaction of the two main variables. The blocks effect was not significant $[F(7.196)=1.97 . p>.05]$. nor was the interaction of Schedule by Blocks $(F<1)$. However. significant results were obtained for the Delay by Blocks interaction $[F(7,196)=2.86, p<.01]$ and the Schedule by Delay by Blocks interaction $[F(7.196)=2.91$. $p<.01]$. Tests of simple effects showed that the two partial groups combined ran significantly faster than the continuous group $[F(1.38)=42.52 . p<.001]$. The comparison between the two partial groups. as well as the comparison between the continuous delay group and each of the other three groups yielded nonsignificant results. The same test showed that the partially rewarded 
Ss ran significantly faster than the continuously rewarded Ss $[F(1.28)=5.05, p<.05]$. The comparison between the partial delay group and the continuous reward group approached significance $[F(1,28)=3.12$. $.05<\mathrm{p}<.10$ ]. which was probably due to the marked increase in performance of the continuously rewarded Ss during the first two blocks of Phase 2. This is supported by the fact that. when each group's performance on the last trial of Phase 1 was compared with the group's mean performance on the first block of Phase 2. only the comparison for the continuous reward group yielded significant results $[t(7)=3.49, p<.02]$. Moreover. a simple two-way analysis of variance that excluded the first two blocks of Phase 2 was performed, yielding a significant schedule effect $[F(1,28)=4.41, p<.05]$. Neither the delay nor the Schedule by Delay interaction was significant: $F<1$ for delay and $F(1,28)=2.35$. $p>.05$ for the interaction. Tests of simple effects showed that both the partial reward group and the partial delay group ran significantly faster than the continuous reward group $[F(1,28)=6.61, p<.025$ and $\mathrm{F}(1,28)=4.34 . \mathrm{p}<.05$. respectively]. There was no significant difference between the continuous delay group and the continuous reward group $[\mathrm{F}(1.28)=2.83$. $p>$.05].

Further tests of simple effects were performed to compare the performance of the groups across the eight trial blocks. The statistical analysis supports the graphical one in that the continuously rewarded Ss showed a greater decrement over trials than those in the continuous delay group $[F(7.196)=5.76 . p<.01]$, the partial reward group $[F(7.196)=2.41, p<.05]$. and the partial delay group $[F(7.196)=2.40, p<.05]$. No significant difference over blocks was detected between either the two partial groups or between each one and the continuous delay group.

\section{DISCUSSION}

The present results clearly support the two hypotheses tested in this study. First, positive transfer was obtained after minimal acquisition. i.e.. Ss previously trained under either partial reward or partial delay conditions showed greater persistence during continuous delay than Ss trained under continuous reward conditions. Second. there was no difference between the two partial groups. indicating that the transfer between nonreward and delay of reward was complete. These results are almost identical to those obtained earlier following extended training (Shanab. 1971).

The multiple-pellet frustration hypothesis (Amsel et al. 1968) seems best suited to aceount for the results. Introduction of delay following experience with reward is assumed to produce primary frustration $\left(R_{1}\right)$ responses similar to those produced by frustrative nonreward (Amsel. 1958). At firse amticipatons

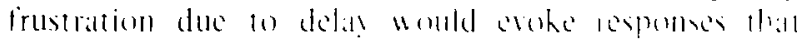

interfere with the ongoing goal-approach response, but later these anticipatory responses and their feedback stimuli, or the $r_{I}-s_{I}$ mechanism, become counterconditioned to the ongoing response. Since Ss in the continuous partial delay and partial reward groups have already learned through the $\mathrm{r}_{\mathrm{F}}-\mathrm{S}_{\mathrm{F}}$ mechanism to make the instrumental approach response in the presence of delay or nonreward cues, the performance of the three groups should converge to the same level. On the other hand, when $S s$ in the continuous reward group are shifted to the continuous delay condition. they would experience primary frustration $\left(R_{F}\right)$ due to delay. which would be reflected in unconditioned avoidance responses. To be sure. anticipatory frustration due to delay would be formed, but. in this case, it would be conditioned to responses that compete with the learned approach response. This would account for the slower speeds of the continuously rewarded Ss relative $10 \mathrm{Ss}$ in the other three groups.

The present results may be amenable to a primary frustration analysis similar to that used to account for the PREE following a small number of acquisition trials. Brooks (1971) proposed that the PREE following minimal acquisition could be attributed to the greater primary frustration $\left(\mathrm{R}_{\mathrm{F}}\right)$ experienced by the continuously rewarded group as compared to the partially rewarded group. Thus, the present results could be explained in terms of greater primary frustration $\left(\mathrm{R}_{\mathrm{F}}\right)$ due to delay experienced by the continuously rewarded Ss relative to those in the other three groups. However. such a motivational explanation runs into at least two difficulties. Since the effects of motivation on behavior are presumably both rapid and transient. it is not clear why the continuously rewarded Ss took so long after the shift ( 6 days) before showing any decrement in performance. nor why they continued to show such a decrement thereafter relative to the other three groups.

The present findings clearly show that transfer can take place after only six acquisition trials. This finding is similar to the PREE found following minimal acquisition trials. To be sure. some transfer is involved in the latter type of study. Such results seem to indicate that minimal expericnce with frustration-producing conditions is sufficient to produce persistence.

The frustration interpretation of these results does not exclude other interpretations that treat nonreward as the limiting case of delay of reward (cf. Logan. 1960: Capaldi. 1967). For example. Capaldi’s sequential hypothesis (1967). which emphasizes the similarity between the stimulus aftereffects of nonrewarded and delayed trials. can probably account for the present findings on the basis of a greater generalization decrement suffered by the continuous reward group relative to the two partial groups.

\section{REFERENCES}

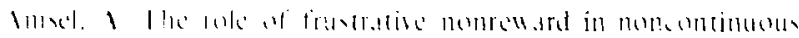


reward situations. Psrchologicil Bulletin. 1958. 55. 102-119.

Amsel. A. Behavioral habituation. counterconditioning and persistence. In A. Black and W. K. Prokas! (Eds.), Classical conditioning II. New York: Appleton-Century-Crofts, 1972.

Amsel. A.. Hug. J. J.. \& Surridge. C. T. Number of food pellets. goal approaches. and the partial reinforcement effect after mininal acquisition. Journal of Experimental Psychology. $1968,77.530-534$

Brooks. C. I. Frustration considerations of the small-trials partial reinforcement effect: Experience with nonreward and intertrial reintoriement. Journal of Experimental Psychology. 1971. 89. 362-371.

Capaldi. E. J. A sequential hypothesis of instrumental learning. In K. II. Spence and J. T. Spence (Eds.). The psichology of learning and motivation. Vol 1. Nell York: Academic Press. 1967.

Capaldi. E. J.. \& Waters. R. W. Conditioning and nonconditioning interpretations of small-trial phenomena. Journal of Experimental Pstchology. 1970. 84. 518-522.
Glazer. H.. \& Amsel. A. Transfer of persistence effects from frustration produced by blocking to frustration produced by nonreinforcement. Psychonomic Science. 1970. 18. $311-312$.

Logan, F. A. Incentive. New Haven: Yale Lniversity Press. 1960.

McCain. G. Partial reinforcement effects following a small number of acquisition trials. Ps!chonomic Monograph Supplements, 1966. 1, 251-270.

Shanab. M. E. Positive transfer between nonreward and delay: Journal of Experimental Psychology. 1971. 91. 98-102.

Terris. W.. \& Wechkin. S. Learning to resist the effects of punishment. Psychonomic Science, 1967. 7, 169-170.

Wagner. A. R. Frustrative nonreward: A variety of punishment. In B. A. Campbell and R. M. Church (Eds.), Punishment and arersile behalior. New' York: Appleton-Century-Crofts. 1969. Pp. 157-181.

(Received for publication October 10, 1972: revision received A pril 12, 1973.) 